\title{
Doing it Differently
}

\section{Systems for rethinking infrastructure}

Second edition 
Downloaded by [] on [26/04/23]. Copyright @ ICE Publishing, all rights reserved. 


\section{Doing it Differently}

Systems for rethinking infrastructure

\section{Second edition}

David Blockley and Patrick Godfrey 
Published by ICE Publishing, One Great George Street, Westminster, London SW1P 3AA

Full details of ICE Publishing sales representatives and distributors can be found at: www.icebookshop.com/bookshop_contact.asp

\section{Other titles by ICE Publishing:}

Construction Planning, Second edition.

D. Neale et al. ISBN 978-0-7277-6057-9

Programme Management in Construction.

A. Haidar et al. ISBN 978-0-7277-6014-2

Risk Analysis and Management for Projects (RAMP), Third edition.

Institution of Civil Engineers. ISBN 978-0-7277-4157-8

www.icebookshop.com

A catalogue record for this book is available from the British Library

ISBN 978-0-7277-6082-1

(c) Thomas Telford Limited 2017

ICE Publishing is a division of Thomas Telford Ltd, a wholly owned subsidiary of the Institution of Civil Engineers (ICE).

All rights, including translation, reserved. Except as permitted by the Copyright, Designs and Patents Act 1988, no part of this publication may be reproduced, stored in a retrieval system or transmitted in any form or by any means, electronic, mechanical, photocopying or otherwise, without the prior written permission of the Publisher, ICE Publishing, One Great George Street, Westminster, London SW1P 3AA.

This book is published on the understanding that the authors are solely responsible for the statements made and opinions expressed in it and that its publication does not necessarily imply that such statements and/or opinions are or reflect the views or opinions of the publishers. While every effort has been made to ensure that the statements made and the opinions expressed in this publication provide a safe and accurate guide, no liability or responsibility can be accepted in this respect by the authors or publisher.

While every reasonable effort has been undertaken by the authors and the publisher to acknowledge copyright on material reproduced, if there has been an oversight please contact the publisher and we will endeavour to correct this upon a reprint.

Commissioning Editor: Amber Thomas

Development Editor: Maria Inês Pinheiro

Production Editor: Rebecca Norris

Market Development Executive: Elizabeth Hobson

Typeset by Academic + Technical, Bristol

Index created by Nigel d'Auvergne

Printed and bound in Great Britain by Bell \& Bain Limited, Glasgow, UK 


\section{Contents}

What people said about the first edition

Preface to the second edition

Preface to the first edition

Acknowledgements

About the authors

Glossary

Part I. The need to do it differently

01

\section{Expecting the unexpected}

1.1. Change is inevitable

1.2. Targeting success for this chapter

1.3. Infrastructure is crucial

1.4 Mission impossible?

1.5. Systems-thinking is a key

1.6. Benefiting from admitting when we do not know

1.7. Recognising that success is in our future

1.8. An owner's tale of legacy, leadership and collaboration

1.9. Checking for success

References

02

2.1 Making sense of our world

2.2. Targeting success for this chapter 25

2.3. Structuring our problems 26

2.4 Systems and boundaries 30

2.6. Checking for success 39

$\begin{array}{ll}\text { References } & 40\end{array}$

03

\section{Everything changes}

3.1. Applying systems-thinking to ourselves 43

3.2. Targeting success for this chapter 43

3.3. Deepening our view of process 44

3.4. Using mind maps $\quad 50$

3.5. Classifying the processes 54

3.6. Defining the attributes of process 56

$\begin{array}{ll}\text { 3.7. Judging through understanding } & 63\end{array}$

3.8. Checking for success 63

$\begin{array}{ll}\text { References } & 64\end{array}$

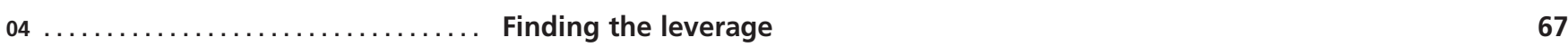

4.1. Wicked and messy complex problems 67

$\begin{array}{ll}\text { 4.2. Targeting success for this chapter } & 67\end{array}$

4.3. Addressing wicked and complex problems 67

4.4. Looking for leverage to target success 69

4.5. Systems-thinking is a way of tackling problems $\quad 74$

$\begin{array}{lr}\text { 4.6. Dealing with connectivity } & 80\end{array}$

4.7. Using appropriate engineering 83

4.8. Checking for success 84

References $\quad 85$

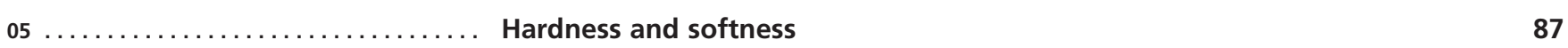

5.1. People are crucial to success $\quad 87$

5.2. Targeting success for this chapter 87

5.3. Unifying hard systems and soft systems 87

5.4. Understanding the subjective and the objective 90

5.5. Testing dependability 92 
5.6. Measuring dependably

5.7. Reasoning with uncertainty 99

5.8. The Italian flag story 104

5.9. Checking for success 108

$\begin{array}{ll}\text { References } & 109\end{array}$

Part III. Making the difference $\quad 111$

06

Rigour through practical foresight $\quad 113$

6.1. The need for practical rigour 113

6.2. Targeting success for this chapter 114

6.3. Rethinking infrastructure 114

$\begin{array}{ll}\text { 6.4. Thinking as a skill } & 117\end{array}$

6.5. Looking outwards - synthesising the overview 123

6.6. Looking inwards - analysing the parts 124

6.7. Reflective practice 126

6.8. Engineering wisdom and judgement 132

6.9. Checking for success 134

References $\quad 135$

$07 \ldots \ldots \ldots \ldots \ldots \ldots \ldots \ldots \ldots \ldots \ldots \ldots \ldots \ldots+$ Making the most of our learning journeys 137

7.1 Why a journey? 137

7.2. Targeting success for this chapter 139

7.3. The journey has many stages 140

7.4. We need to distinguish between complexity, complicatedness and chaos $\quad 144$

7.5. Strategies for learning your way out of complexity 146

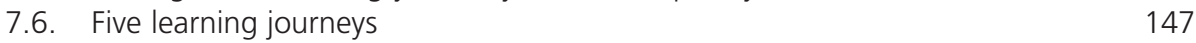

7.7. Improving through learning in three common examples 148

$\begin{array}{ll}\text { 7.8. Checking for success } & 149\end{array}$

References 150

$08 \ldots \ldots \ldots \ldots \ldots \ldots \ldots \ldots \ldots \ldots \ldots$ Delivering quality 151

8.1. The questions 151

8.2. Targeting success for this chapter 152

8.3. Motivating and rewarding quality 152

8.4. Behaving ethically 156

8.5. Understanding the risks 158

8.6. Risk is in the future 161

8.7. Plan for contingencies 163

8.8. Checking for success 171

$\begin{array}{ll}\text { References } & 171\end{array}$

$09 \ldots \ldots \ldots \ldots \ldots \ldots \ldots \ldots \ldots \ldots$ Inspiring the team 173

9.1. People are the root of success and failure 173

9.2. Targeting success for this chapter 173

9.3. Building and motivating the team 174

9.4. Team learning 175

9.5. Understanding leadership 178

9.6. Recognising interdependence 180

9.7. Sharing the vision 182

9.8. Developing personal excellence 183

9.9. Looking for personal success 185

9.10. Looking for win-win 187

9.11. Developing yourself as a systems technical leader 190

9.12. Checking for success 192

References 193

$10 \ldots \ldots \ldots \ldots \ldots \ldots \ldots \ldots \ldots \ldots \ldots \ldots$ Looking to the future $19 \ldots \ldots$

10.1. Creating a vision for systems engineering 195

10.2. Targeting success for this chapter 195 
10.3. Providing for fundamental needs in a globally competitive environment 196

$\begin{array}{ll}\text { 10.4. Integrating socio-physical systems } & 197\end{array}$

10.5. Learning journeys facilitate dependable transformative change 198

10.6. Fundable infrastructure 199

10.7. An impelling proposition for the totality of infrastructure systems 200

10.8. Summarising and checking for overall success 200

$\begin{array}{ll}\text { 10.9. Checking for success } & 201\end{array}$

References 203

Appendix A . . . . $\ldots \ldots \ldots \ldots \ldots \ldots$ Infrastructure digital technology requires systems-thinking 205

$\begin{array}{ll}\text { Initially there was CAD } & 205\end{array}$

Now there is BIM 205

BIM software represents data in object-oriented models tied to relational data bases 206

$\begin{array}{ll}\text { Advanced BIM will require systems-thinking } & 207\end{array}$

$\begin{array}{ll}\text { Other IT developments } & 209\end{array}$

$\begin{array}{ll}\text { References } & 210\end{array}$

Appendix B $\ldots \ldots \ldots \ldots \ldots \ldots \ldots \ldots$ Contracts informed by systems-thinking can overcome the silo effect 213

$\begin{array}{ll}\text { References } & 215\end{array}$

Appendix $C \ldots \ldots \ldots \ldots \ldots \ldots \ldots \ldots$ A very brief history of the gestation of systems-thinking 217

$\begin{array}{ll}\text { References } & 221\end{array}$

$\begin{array}{ll}\text { Index } & 223\end{array}$ 
Downloaded by [] on [26/04/23]. Copyright @ ICE Publishing, all rights reserved. 


\section{What people said about the first edition}

'I hope you find this book, Doing it Differently, an informative and useful text. It is a book that provides numerous tools, techniques and case studies that will help those motivated to change the way things are done within construction to succeed.

I also hope that it will encourage both clients and industry to explore the concepts outlined in the Government's report Rethinking Construction, and help them to continue to develop its basic ideas focused on the customer process and people.'

Sir John Egan

Chairman, Construction Task Force

'When Rethinking Construction was launched in July 1998 it led to a wide range of responses in construction. Many of these have stemmed from concerns of individuals regarding their own understanding of the whole picture and what they can do to make things better. In Doing it Differently - Systems for Rethinking Construction,

David Blockley and Patrick Godfrey challenge readers to stand aside from present roles and look at every aspect of construction, starting with why a particular construction product is required at all. After reading Doing it Differently one can see why the key route to construction improvement is through rethinking, and one has the tools to make it happen.'

Martin Reynolds

Chairman, Construction Round Table, 1998-1999 Member, Movement for Innovation Board, 1998

'With the increasing involvement of competition in the water industry and at a time when water companies are required to reduce their charges substantially and yet meet higher quality standards, there is a real need for change. The innovative ideas in this book will certainly help us to reduce construction costs and deliver an even better standard of service to our customers.'

John Browning

Managing Director, Bristol Water Holdings plc

'This is a serious and impressive work, which covers a lot of ground. It will help those who are committed to changing the industry to create structures to do so, whether in one area or in totality. It offers a whole range of powerful tools, which will be particularly useful to those with the personal drive to apply themselves to rethinking construction. It is packed with examples that help to flesh out a rigorous analysis of how the industry can improve.'

David Fison

Executive Vice President, Kvaerner Construction

Gold Medal in the category of Managing Construction

Author of the Year 2001 
Downloaded by [] on [26/04/23]. Copyright @ ICE Publishing, all rights reserved. 


\section{Preface to the second edition}

If you are concerned about the security and integrity of the infrastructure of the locality, city, region, country and world you live in then this is a book for you. While the first edition was aimed at construction professionals, our target readership for this second edition is much wider. In the first edition we promoted 'joined-up' systems-thinking for construction professionals. Our aim for this second edition is to persuade you that systems-thinking is important for everyone concerned about our infrastructure. We do it because our old certainties are disappearing. We maintain that 21 st century democratic countries are being challenged with some troubling, deep-seated and complex issues that require us to 'learn together' and to collaborate in new ways.

In 2000, the rapidly changing expectations of the clients of the construction industry were posing a challenge. The industry was being asked, in the Egan Report, 'to do it entirely differently'. The first edition of this book was a response to that challenge by promoting systems-thinking as a way of meeting targets to (a) deliver new customerfocused strategies, (b) work back from success, (c) realise values by integrating people and process, (d) generate simplicity out of complexity by process mind mapping, (e) inject practical rigour and (f) create tools for managing uncertainty.

Now in 2016 things have moved on. As always there is good and bad news. The good news is that governments around the world (including the UK, the USA and those of Europe) have realised the need to invest in their infrastructure and have issued national infrastructure plans. There have been significant changes and many improvements in the construction industry, although success is patchy. The American Society of Civil Engineers graded America's response to infrastructure renewal in 2014 as D+, which they define as 'poor' and 'at risk' (but at least it has improved from a D in 2009). Perhaps the best and most well-known achievement in the UK was the magnificent London 2012 Olympics construction programme. Less well known perhaps is the way different construction organisations have taken an integrated approach through the UK Constructing Excellence initiative (2016). The good news about the promoting of systems-thinking is that it has been received with intoxicating enthusiasm from some, although it has to be said that it tends to polarise opinion and has evoked fierce opposition from others. The UK's senior engineering body, the Royal Academy of Engineering, has supported it by issuing the report Creating Systems that Work: Principles of Engineering Systems for the 21st Century (2007).

The bad news is that we are realising that the 21 st century is revealing new challenges. New complexities through subtle interdependencies are making joined-up thinking and long-term predictions far from straightforward. Two examples are climate and social change. More than ever our approach to flooding needs new joined-up thinking, and no matter what we think of the forecasts of climate scientists there seems little doubt we are in for a period of extreme weather. Whatever the reasons for the severe climatic events we have to cope with the effects, but they are almost impossible to predict. The phrase 'Save the planet' may be the most misleading ever: the planet will be fine, what is at stake is the probable and unnecessary suffering of large numbers of people as we become more vulnerable to unforeseen disasters and catastrophes. The consequence is that we now must pay much more regard to ideas of resilience, robustness, vulnerability and adaptability, as well as sustainability. Other issues are to do with the fact that our social landscape is ever changing, with population growth and greater numbers of older people placing different requirements on our infrastructure, including education and health. The pace of change driven by digital technology is creating both challenges and opportunities. We seem, as well, to be failing to persuade enough young people, and particularly women, that engineering is a fulfilling career. The forecasts of shortages in recruitment are disturbing and in many people's view these are due to long-standing deep-seated cultural 'image-problems' of the inferiority of vocational practical work over academic purity.

The central message of the first edition remains, but we write the second edition with a renewed, even more urgent and wider imperative. Our infrastructure and built environment is critically important to everyone - its users, construction professionals, 
the wider community of professionals (including health and education), as well as politicians and the general public. Every day we all use buildings, transport,

communications, water and waste systems, energy supply systems, schools and hospitals. So in this new edition we will address infrastructure in a sense that is much wider than construction. The needs of the users of infrastructure should be seen as the driver for change. We include, for example, electricity supply, delivery of gas and oil and renewable energy, telecommunications (including mobile and wireless networks), railways and roads, buildings, emergency and community services, as well as new modes of transport such as lightweight autonomous vehicles that embody clean technology and low emissions. Perhaps most challenging of all is the need to rethink our cities so that they are resilient in the face of unknown challenges ahead.

The UK National Infrastructure Plan 2014 recognises that 'Improving ... productivity is a vital element of ... long term economic planning. High-quality infrastructure boosts productivity and competitiveness.' The UK government wants 'a relentless focus on ... delivering ... projects faster, better and more cost effectively by streamlining the planning regime; developing a robust and transparent pipeline of projects and programmes; ensuring the right skills and capacity are in place; reducing infrastructure costs; adopting a more intelligent approach to procurement; and developing best practice to inform how infrastructure projects are managed and run.' US policy states that 'efforts shall address the security and resilience of critical infrastructure in an integrated, holistic manner to reflect this infrastructure's interconnectedness and interdependency.'

The message of this book is that tackling these complex issues requires us all to think and act differently towards the things that we usually simply take for granted - we all must do it differently. And if we are to do that then we all - technical and non-technical readers alike - have to understand the need. Without that understanding we will not be willing to invest time in learning, developing and using new ideas, methods, techniques and tools. We have, therefore, retained the division of the book into three parts as set out in the Preface to the 1st edition.

REFERENCES

Royal Academy of Engineering (2007) Creating Systems that Work: Principles of Engineering Systems for the 21st Century. Royal Academy of Engineering, London, UK. See http://www.raeng.org.uk/publications/reports/rae-systems-report (accessed 17/11/2016).

UK Constructing Excellence (2016) About constructing excellence. See http://constructingexcellence.org.uk/about/ (accessed 17/11/2016). 


\section{Preface to the first edition}

The rapidly changing expectations of the clients of the construction industry are posing a challenge. The players in the construction industry have been invited 'to join with government and major clients to do it entirely differently' (Rethinking Construction - The Egan Report, DETR, 1998). Many of the major clients of the industry are committed to dramatic change - but without prescribing the way it should be done. They have adopted what can be called a 'success targeted approach'. They have challenged themselves and the complete supply chain to find ways of delivering the change by Rethinking Construction.

If we are indeed to do it differently we have to understand the need. Without that understanding we will not be willing to invest time in learning, developing and using a new toolkit - that of thinking differently. This book is written as a contribution to that new toolkit to help make the difference. There are tantalising rewards for those who grasp the opportunities, and risks to those who are not prepared to change.

Many readers will prefer to address the application before investing effort in getting to grips with the tools to do it. We have therefore divided the book into three parts and provided many cross-references to allow you to choose your route.

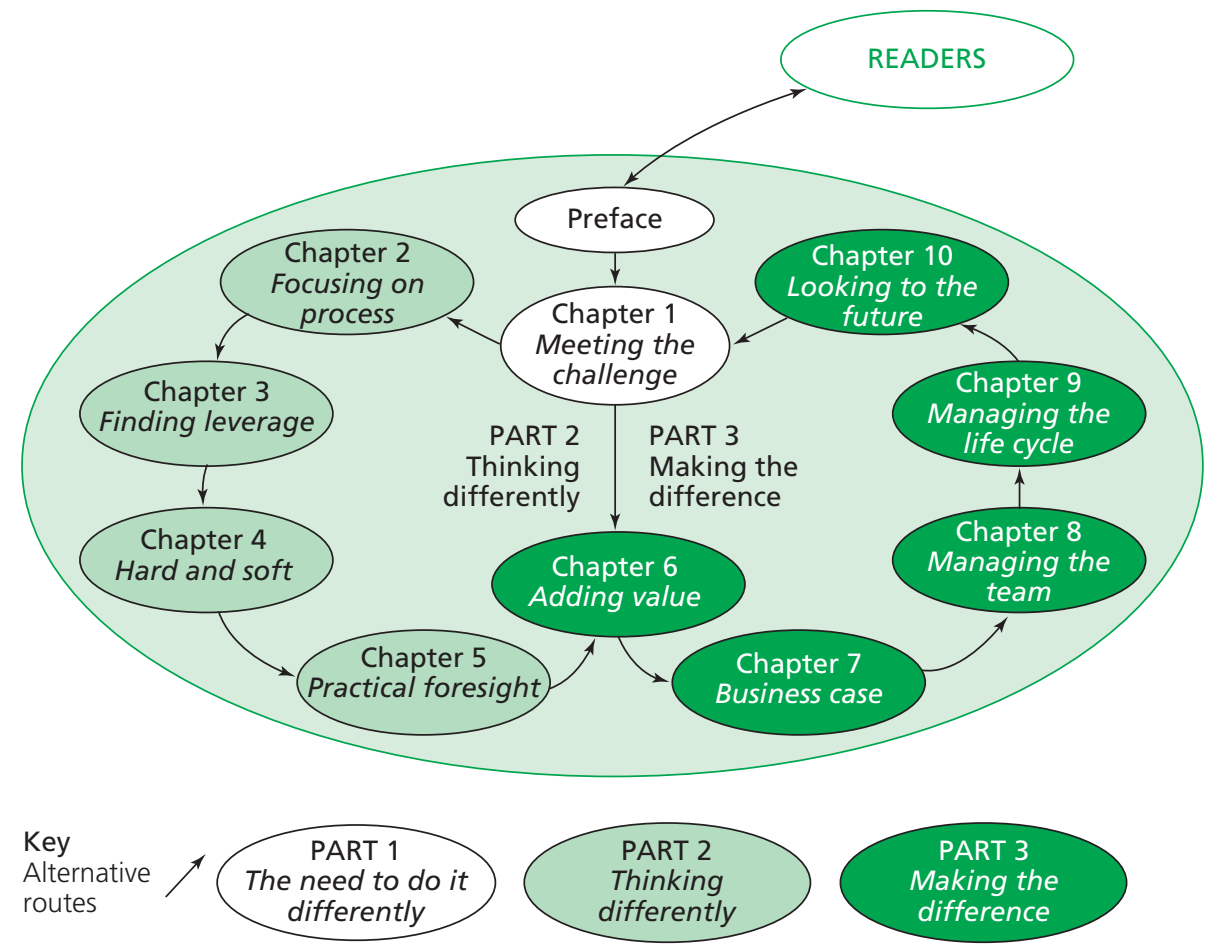

In the Preface and Part 1 of the book we set out the need to think differently to meet the Egan challenge. In Part 2 (Chapters 2-5) we explain the toolkit - that of thinking differently - which we believe is required to meet the challenge. In Part 3 (Chapters 6-10) we talk about making the difference in the life cycle of the total construction process.

We have purposely written the text so that after reading Part 1 you may progress to Part 2 or Part 3 according to your taste. Those who feel the need to read about the way in which we can make a difference should progress immediately to Part 3 . Those who prefer to understand something of the toolkit should go first to Part 2. Another strategy might be to speed read one section before reading the other in depth. We hope that by making the purpose of each part and, in turn, of each chapter reasonably clear you will be able to choose a strategy which is appropriate for you. There is a risk in this approach which is that we might be accused of repeating ourselves in places particularly between Parts 1 and 2. We have consciously made some points which are 
important in more than one context. Depending on how you have chosen to read the book, you may or may not have read the point earlier set in a different context. A good example is the importance of recognising our different points of view in teamwork. We try always to build on an earlier point and bring new learning to a repeated point.

The overall success targets for the book are to enable you as a construction player to:

- deliver new customer focused strategies

- work back from success

- realise values by integrating people and process

- generate simplicity out of complexity by process mind mapping

- inject practical rigour

- create tools for managing uncertainty.

The success targeted process of this book consists of four phases. Firstly, while writing the book we have prototyped the ideas with a range of construction players. Secondly, we ask you to read the book. Thirdly, we ask you to return the feedback form at the end of the book. Fourthly, we will analyse the feedback and publish the results on the internet. We will endeavour to synthesise the feedback to produce agreed success targets and then report on progress to those successful conclusions. We will chart as many successful changes as we can within the resources we can muster to do it. We include in Chapter 10, as a start to this process, the lessons we have learned through the actual writing of this book.

The practical examples we have used to illustrate the points we make in the book all stem from our personal experience and that of the large number of people who have helped us in the development of this book. We have made them anonymous in order to prevent any misunderstandings or not to break commercial confidences.

We have used the male gender in our writing but we wish to stress that this is not because we undervalue the contribution of women to the construction industry - far from it - we use it purely to keep the language as simple as we can.

We dedicate this book to our wives Karen Blockley and Trudi Godfrey who have been totally supportive and long-suffering in the absence of their husbands as we talked for long hours on the telephone, read e-mails of latest drafts, met in the evenings over bought-in pizzas.

We thank Jim Hall for reading a draft of the whole book and for providing several insights. We thank Martin Thomas for discussions from which many illuminating ideas emerged. We thank Tony Allum, Stephen Barr, Adrian Baxter, Hugh Beasley, Liz Daly, Daniel Godfrey, Jim Haile, David Hall, David Hancock, Norman Haste, Marcus Hayes, Paul Honeywell, Jason Le Masurier, John Lofty, Tony Madden, Keith Marr, John Murphy, Derek Pollock and Roger Wyatt for providing material and for making suggestions, commenting on specific pieces and helping us to improve our original text. We thank Vassos Chrysostomou for a useful discussion on CALIBRE and for permission to include Figs 9.20 and 9.21. We thank Neil Allan, Jitendra Argawal, Alberto Bernardini, Arturo Bignoli, John Davis, Bill Dester, David Elms, David Muir Wood, David Platt and Norman Woodman for many helpful and interesting insights. We thank all other colleagues at Halcrow, and past and present research assistants and postgraduates at the University of Bristol who have helped form and hone many of the ideas which inspired this book.

Last but not least we thank Ann Fitzgerald for her ability to fix up meetings when diaries seemed totally full and to keep Patrick generally well organised.

David Blockley

Patrick Godfrey

Bristol, 2000 
We thank all our colleagues we mentioned in the first edition again for their discussions, comments, insights and help. In particular, for this second edition we thank Paul Wilkinson for his useful comments on BIM and Appendix A, and Patrick's son Daniel for his critical reflections. We thank Neil Carhart for his contribution to Box 2.2 on problem structuring methods, and David Martin for providing Figure 1.8.

Thanks are also due to colleagues at the University of Bristol and from industry for many conversations and interactions that have informed the redrafting. These include Oksana Kasyutich, Rachel Freeman, Ruth Deakin-Crick, Ges Rosenberg, Theo Tryfonas, Jonathan Rees, Mike Yearworth, Sean Shields, Colin Taylor, Chris McMahon, Ben Hicks and Sally Heslop from the university, and Charlotte Dunford, Steven Barr, Richard Beasley, David Oxenham, Hillary Sillitto, Anne O'Neil, Peter Head and Duncan Kemp from industry. We thank Sophie Causon-Woods for her infinite patience and good humour in keeping Patrick organised when in Bristol. We thank Maria Inês Pinheiro, Development Editor, and Rebecca Norris, Production Editor, at ICE Publishing, as well as Julie Gorman and Rich Cutler at Helius for copy-editing and proofreading, and Nigel d'Auvergne for indexing, for making this book work.

Last, but by no means least, we thank and are in great debt to our wives Karen Blockley and Trudi Godfrey, who have been totally patient and supportive. 
Downloaded by [] on [26/04/23]. Copyright @ ICE Publishing, all rights reserved. 


\section{About the authors}

\section{David I. Blockley BEng PhD DSc FREng FICE FIStructE}

Emeritus Professor Civil Engineering, University of Bristol, UK

David Blockley was Dean of Engineering at the University of Bristol 1994-1998 and the Head of Civil Engineering 1989-1998 and 2002-2005. He was President of the Institution of Structural Engineers in 2001-2002, a Non-Executive Director of Bristol Water 2001-2011, and has been a technical consultant on a number of projects.

David also worked on design development as a Development Engineer with the British Constructional Steelwork Association in the late 1960s. He is the author of over 180 papers and seven books, and has won several technical awards for his work, including the Telford Gold Medal and the George Stephenson Medal of the Institution of Civil Engineers.

Patrick S. Godfrey BSc DEng(Hon) FREng FICE FEI FCGI FINCOSE

Emeritus Professor Systems Engineering, University of Bristol, UK

Patrick Godfrey was Director of the Systems Centre and the EPSRC Industrial Doctorate Centre in Systems at the University of Bristol and University of Bath 2005-2016. Before that he was a Director at Halcrow, specialising in the design of offshore oil and gas structures and pioneering new ways of managing the complete life cycle of large construction projects. From 1996 to 2001 he provided strategic risk management consultancy services to BAA for the development of Terminal 5. He is a Fellow of the Royal Academy of Engineering, the Institution of Civil Engineers, the City and Guilds Institute, the Energy Institute and INCOSE, and is an Honorary Fellow of the Institute of Actuaries. 
Downloaded by [] on [26/04/23]. Copyright @ ICE Publishing, all rights reserved. 


\section{Glossary}

The following is a list of some of the important terms used in the book. Some extracts are from D. Blockley (2005), The New Penguin Dictionary of Civil Engineering (Penguin Books). Words in italics are separately described.

active information

appropriateness

attributes

axiom

BIM

chaos

chaos theory

closed system

complex

complicated

contingent

corollary

Cynefin

dependability
Constantly changing, dynamic and possibly self-organising information such as speech or social media.

Suitable or proper in a particular context. An appropriate model is one that is not completely true or precise but which is dependable enough to serve the purpose intended in a specific context (i.e. fit for purpose). Clearly, if a model is true then it is dependable, but it may not be appropriate because it is too detailed and out of context. For example, Newtonian mechanics has been replaced by relativity theory in astrophysics because the latter can deal with problems where velocities approach the speed of light. However, relativity theory is inappropriate for bridge design, since it deals with a level of behaviour of a material that is not relevant.

The characteristic, inherent quality or feature of something. The six attributes of a process can be classified as why, how, who, what, when and where (see process).

An accepted statement assumed without proof.

Building Information Modelling.

Utter confusion, disorder and lack of organisation.

The study of non-linear systems that show great sensitivity to initial conditions (cf. chaos, uncertainty). These dynamic systems, viewed from a traditional perspective, seem to behave randomly and yet conform to a pattern. They can reach a state where if the system is started with a set of initial conditions A fractionally different from another set of initial conditions B, then after a few cycles the two behaviours become very different - this has been demonstrated both theoretically and experimentally. These results imply that there are quite severe limitations in our ability to predict what might happen in such a system - it is chaotic. Chaos theory has produced some interesting results for simple small-degree-of-freedom problems; however, there is much to learn about large-degree-offreedom systems. Applications to management theory that have been promoted are illustrative only. A system in which all of the subsystems, elements or holons within it or all of the factors affecting it are precisely defined and all relationships are known. It has clear boundaries and limited and predictable cross-boundary interactions. The total set of possible outcomes is known, although it may be that only the probabilities are calculable. The assumption that the sum of the probabilities across the sample space is equal to 1 is a closed-world one (cf. open world).

Complex systems are difficult to describe and predict because they have many interconnected parts with emergent properties. They may, under certain conditions, behave in a chaotic way. Complexity theory is the study of how both complex and complicated systems exhibit simple behaviours (cf. chaos theory). High complexity in a project or organisation is associated with tight spacing of equipment, close production steps, many common mode connections, a limited possibility of isolating failed components, limited awareness of interdependencies because of specialisations, limited ability to substitute, unintended feedback loops, interacting control parameters, limited understanding of social processes and tightly coupled systems. A complex system is not just complicated but may be incomplete, with emergent properties from interdependencies that are unknown and unforeseen. They often cannot be 'solved'; rather, they have to be managed to desirable outcomes.

A complicated system may contain lots of elaborately interconnected subsystems or holons. To the non-expert, complicated systems may seem complex, but to an expert each of the subsystems may be tame (i.e. understandable and predictable). There may be sufficient experience and knowledge for dependable design (e.g. for the jet turbine).

Dependent on something uncertain. Used to identify models where the uncertainty is contingent on the starting conditions, as is the case for many complexity science models.

Something that is a natural consequence of something else.

A sense making framework developed by C. F. Kurtz and D. J. Snowden (2003), 'The new dynamics of strategy: sense-making in a complex and complicated world', IBM Systems Journal 42(3): 462-483.

Being dependable, trustworthy and reliable. Practitioners require information that is sufficiently dependable for the decisions they make. Truth is sufficient but not necessary for dependability. For example, Newton's laws are not strictly true in that propositions can be deduced that do not 


\section{deterministic}

\section{duty of care}

emergent property

ethics

\section{fuzziness}

hard system correspond with the facts for bodies travelling at velocities near the speed of light. However, for all practical engineering purposes on the surface of the Earth, Newton's laws are true. Other theories are dependable only when the practitioner is aware of the context (e.g. elasticity in steel is dependable for small strains but not for large plastic strains). There are four sufficient conditions for a proposition to be dependable: (1) a highly repeatable experiment can be set up to test it; (2) the resulting state is clearly definable and repeatable; (3) the value of the resulting state is measurable and repeatable; (4) the test is successful. Note that these conditions are sufficient but are not necessary. Deficiencies in any of these conditions result in a loss of dependability.

The philosophy that all events are totally determined by previous events with no uncertainty. This, perhaps rather surprisingly, is the philosophy of Newtonian mechanics as used in engineering science. However, the practical implementation of it in engineering is non-deterministic (see model, practical rigour and chaos).

A duty of care is an obligation to not act negligently under the law of tort - an obligation to take reasonable care to avoid foreseeable harm to another person or property. A duty holder is someone taking on a set of responsibilities where there is a duty of care.

A property of a whole that emerges from the interactions of the parts. It is the reason why a whole is more than the sum of its parts. It is a property that applies to the whole and not to the parts. For example, an emergent property of you and me is that we can talk and walk; an emergent property of gas molecules is pressure, and of steel crystals is yield strength.

The discipline of moral conduct. It is a set of standards by which a particular group or community decides to regulate its behaviour to distinguish what is acceptable in pursuit of its aims and what is not. In ordinary discourse, the words morals and ethics are used interchangeably. Engineering ethics involves normative enquiries aimed at identifying and justifying morally desirable norms and standards that ought to guide us. The 'golden rule' is found in almost all religions in various forms, that is, 'do unto others as you would have them do to you'. There is no golden rule specifically for engineering, but there is a duty of care to apply professional knowledge and skills responsibly. Ethics is about managing difference and making choices about individual, family, work and societal issues. Professional institutions and society have their own rules of conduct expressed in a code of behaviour. Are ethics absolute or relative? Philosophers have failed to find any absolute rules. There is a hard core of principles with which almost everyone would agree, but it seems that it is always possible to find a counter-example for any general rule that places one rule over another. For example, while being honest is an important principle there are circumstances where a white lie may be justified. One of the chief structural elements of uncertainty: vagueness and imprecision. For example, the statement that 'the stress in a beam is low' conveys meaning and is useful but is not very precise. Fuzzy sets were developed to allow reasoning with vague terms as linguistic variables. Thus, we can form a fuzzy set with the meaning 'low stress'. In classical set theory this is not possible because an element is either a member of a set or it is not. A fuzzy set has elements that have a degree of membership that varies over the interval $[0,1]$, indicating a degree of belief that the element is in the set. Fuzzy logic is logical reasoning with fuzzy sets. A fuzzy relation is a fuzzy set that expresses a relation between two fuzzy sets and is a linguistic variable (e.g. 'approximately equals' or 'much greater than'). It is defined on the Cartesian product that for two sets $X$ (containing points $x_{1}$, $\left.x_{2}, \ldots, x_{m}\right)$ and $Y$ (containing points $\left.y_{1}, y_{2}, \ldots, y_{n}\right)$ is the set of all pairs $\left(x_{i}, y_{j}\right)$.

Any physical system such as a building structure or railway line that involves action and reaction (cf. soft systems, which involve people). Hard systems do not depend on who is interacting with the system: they are assumed to be independent of the observer, and hence are the same for all of us. Our collective understanding has developed through the physical sciences, particularly those that underpin engineering, such as mechanics. The parameters are measurable, the methodology is clear and the results normally quite dependable. Relationships are usually expressed as deterministic functions. They are hard in the sense that they are clear, quite precise, predictive and testable. Clearly, there are hard systems problems that continue to be difficult (e.g. soil behaviour and structural fatigue). Non-linear system behaviour is increasingly becoming important as we realise the limits on the predictability of such systems (see chaos theory). All designed hard systems have a role in a soft system process, and it is in this sense that all hard systems are embedded in soft systems. For example, a beam in a building has the function of carrying loads from the floor slab and passing them onto the columns, and so on down to the foundations. The steel and concrete do not 'know' that that is what they are doing - the functionality is ascribed to it through the soft system process of using the building (i.e. the people who conceived it, designed it, built it and use it). Natural hard systems such as a lake do not have designed function but they do take roles in soft system processes (e.g. as part of a tourist attraction, 
hazard

\section{hierarchy}

holon

impelling proposition

incompleteness

infrastructure

intentionality

interdependence

intersubjective

Italian flag

learning journey as a water sports attraction, a habitat for a rare species of fish or as a reservoir). In the past we have failed to understand that all hard systems are set within soft systems because we have collectively failed to understand sufficiently that humans are intimately connected to their environment.

A state of the world or state of affairs - a condition within a process with a potential for harm. For example, a trailing wire that someone could trip on has the potential for human injury or death; a wind load has the potential for damage to property; processes resulting in climate change have the potential for damage to the environment; a decision that results in loss of share price has the potential for economic loss; and not working hard enough to pass an examination has the potential for failure to meet objectives. Hazards exist in the past, present and future, whereas risk exists only in the future. Hazard analysis is the systematic search for hazards in a system, whether hard or soft. Hazard management is the control of hazards by removing them, if at all possible, reducing them by redesigning or modifying the system, and finally by remedying them so that the risk is acceptable.

Levels of description of a system, so that at each level the lower levels are subsystems of the higher levels - describing systems within systems within systems. Evolution in complex systems leads to differentiation in multi-level hierarchies. A hierarchical model is a graphical representation of a concept or idea in the form of a hierarchy.

Anything considered at the same time to be both a part and a whole. It has emergent properties that derive from the cooperation of the parts. For example, a beam is both a whole (with properties of size, strength and hardness that derive from the molecules of which it is made) and a part (as it contributes to the structure in which it is embedded). A soft system example would be yourself. You are a part (of your family, your neighbourhood, your country, etc.); yet you are also a whole, made up of parts or subsystems (your skeleton, the bones and muscle that make up your structural subsystem, your nervous subsystem, etc.) - and though these are hard systems, we can only understand them through soft systems: us. The attributes that are you (e.g. a good sportsman or a happy person with a positive attitude) emerge from the cooperation of your subsystems.

A statement that can create a collective drive or urge to a central common purpose - it expresses the vision of a team, group or organisation (e.g. for a water company it might be supplying clean, fresh, safe water).

That which we do not know. In any model there will be some things that are purposely excluded and others that perhaps should be included if only we knew they existed. This is an aspect of risk often ignored in formal methods because the theory of probability requires that everything in the sample space be identified and that the probabilities sum to unity. Managing incompleteness (i.e. the unforeseen and unexpected) is the biggest challenge in risk management.

The underlying framework underpinning all of the facilities, services and installations needed for a community, society, city, region or nation to function. It includes buildings, roads, railways, aviation, ports, communication and energy (electrical power, gas) plant and distribution networks, water and food supplies, waste disposal, flood and coastal protection, emergency services, housing and public institutions such as schools and hospitals, and even prisons.

People have intentions - they decide what they want and when they want it. The motivation behind their decisions is rarely obvious and is usually very difficult to identify. The principal attributes of a hard system are action and reaction. A soft system has the extra element of intentionality. It's a bit like throwing a stone in the air (a hard system) but where the stone has a mind of its own and decides to change its trajectory in mid-flight. Relationships are non-linear with bifurcations and instabilities. This means that there are inherent limits to our ability to predict soft systems - because of intentionality, an emergent property of the brain.

Where two processes are mutually dependent. We humans are beginning to understand that we are interdependent with each other and in particular with the physical world, and cannot continue to attempt to dominate it regardless of environmental impact (see sustainability).

Able to be understood or used by a number of people.

A way of articulating the balance of evidence for success, failure and what we do not know. Used as a colourful indicator of an interval probability. For example, in $p(A)=[0.4,0.8]$ the interval $0-0.4$ is coloured green (representing the evidence for success), 0.4-0.8 is white (representing what we do not know and $0.8-1$ is coloured red (representing evidence for failure). Green, white and red are the colours of the Italian flag.

The stages of a learning journey are forming a learning identity and purpose, developing learning power, generating knowledge and know-how, applying or performing learning in authentic contexts and sustaining learning relationships. 
learning organisation

learning power

mental model

\section{messy problems}

mind map

mission statement

model

morals

necessity
Learning is the knowledge and skills acquired through study. It is the changes in behaviour of an individual or organisation arising from experience. It concerns recommendations for what we need to do in the future, made on the basis of past experience. The learning organisation promotes and encourages a culture of learning and of pursuing new knowledge, not just reinforcing existing knowledge. An organisation that maintains a corporate memory to try to prevent the repetition of past mistakes.

Learning power is a set of learning dispositions such as learning to learn, critical curiosity, meaning making, resilience and perseverance, creativity, relationships (valuing interdependence) and strategic awareness (understanding your own learning).

These are the representations, the models, in our minds. We can think of them as patterns (e.g. of electrical activity in our neurons, as patterns of chemical interactions). Memories are patterns in the mind, and through them we have concepts (e.g. of time and identity). To the extent that we think, then we are our mental models. They form our worldviews, they form our opinions and they form our understanding of the physical world. They may be wrong, they may be misconceived, they may define our willingness to pay and they are the basis of our judgements. Imagination and creativity are the result of forming new links between patterns. Through imagination we can build scenarios, think about the past and the future (e.g. risks). Knowledge is a set of mental models, some of which are expressible in natural language. Objective knowledge we share with others, and we are concerned whether it is dependable - true or false. We reason in natural language but we also use formal languages and logic (principally mathematics). Subjective knowledge is within us, and deep within us the subconscious mind contains mental models that control, for example, our heartbeat. Some models can be subconscious part of the time and not at other times (e.g. learned skills such as driving a car). These ideas are important in understanding engineering judgement.

Problems and situations that do not seem to yield to easy solutions. You get the feeling they are rather like a bowl of tangled spaghetti that seems to get more tangled the more you try to sort it out. A means of representing a concept, idea or topic as a map (e.g. drawn on paper or computer). It is built up from a central 'idea' with related ideas radiating out from the centre. The technique of mind mapping is intended as a learning aid, for remembering, understanding and developing ideas; the basic format of a 'radiating linkage' of ideas can be personalised with symbols, colouring and designs.

A high-level statement of the purpose of an organisation. The value of such a statement is often in the process of deciding what it is rather than what it actually says, since the clarification of aims and purpose helps to create a common vision.

A representation of something. It may be physical, such as a three-dimensional (3D) representation of specific aspects of something (e.g. an architectural model of a building). It may also be theoretical (e.g. a mathematical equation representing some physical process). It may be computational (e.g. a computer representation of forces and displacements in a structure such as a finite-element model) or it may be graphical (e.g. a 'walk through' 3D pictorial representation of the interior of a building or an oil rig). Note that as models are representations of a reality they are by definition incomplete, and so describe the world only from a specific point of view. Model analysis is a process of using models combined with appropriate analytical techniques to predict the behaviour of real-world systems (e.g. a structure such as a dam, or the behaviour of a river flow).

Concerned with right and wrong - with what ought to be rather than what is. They are about defining what is good. (Compare ethics, which is the discipline of moral conduct.) In everyday language, the words 'morals' and 'ethics' are used interchangeably. Philosophers argue about how to distinguish moral and non-moral good. Some distinguish by content, some by whether it affects other people, others base it on religion. A moral action is one that can be morally evaluated. Our values underpin our morals, and both set the context for quality - all are crucially important for successful engineering and in fighting off any possibility of corruption.

1. The state of being required to be done or achieved, imperative or indispensable. The necessities of life are food, warmth and shelter. A necessary condition is one that must be fulfilled. Condition A is necessary for condition B if B cannot occur unless A also occurs. For example, safety (A) is necessary for good design (B). In the logical implication 'if A then B' or 'A implies B', B is necessary for A and A is sufficient for B (e.g. 'if (good design) then (safe design)').

2. In interval probability theory using the Italian flag, necessity is a conditional measure of the degree to which the success of a subprocess $\mathrm{E}$ is required for the success of a super-process $\mathrm{H}$ (i.e. $\mathrm{p}(\mathrm{H} / \mathrm{E})$ ). It is the evidence for $\mathrm{H}$ given $\mathrm{E}$ expressed as an interval probability. 
object

objective

open system

passive information

personal mastery

phronesis

practical rigour

practical wisdom

process
An object is anything that, by being to some degree stable or coherent, may be apprehended, perceived, understood or conceived through thought or action.

1. A precise statement of an intended outcome - it is a target for success in a process. An objective should be specific, and you should know clearly when you have reached it. An objective should be SMART (i.e. Specific (i.e. precise and clear), Measurable and Memorable (i.e. you should know when it is achieved or not and you should always remember it easily), Achievable (i.e. not totally beyond your capabilities and resources - it should stretch you but not be unachievable), Realistic (i.e. keep it close to reality and firmly grounded) and Timed (i.e. set a date and programme to attain it).

2. Knowledge and information that is not subjective (i.e. exists outside the mind of any one individual and is available to everyone). We can think of it as all of the books in libraries and all of the information available on the internet. Objective knowledge has an objective existence even though it derives from our collective subjective minds. However, this test of the shared existence of knowledge must not be confused with the test of whether it is true or false. Objective knowledge can be fictional (e.g. Sherlock Holmes and mermaids), and it can be wrong or false. Engineers need objective knowledge that is dependable.

A system where we need to think about transfers of energy, resources, materials, equipment, information and many other forms of flow across boundaries.

Information that changes only slowly, for example as the pages of a book deteriorate and become difficult to read.

A commitment continually to clarify and develop our personal vision, to focus energies, to develop patience and to see reality. It is the cornerstone of the learning organisation. It is the discipline of personal growth that goes beyond competence and skills though it is grounded in them.

An alternative phrase could be 'personal excellence', because it derives from our personal habits.

The juxtaposition of vision (where we want to be) with a clear picture of the current reality (where we are relative to where we want to be) generates a creative tension. Personal mastery is learning how to generate and sustain creative tension in our lives.

Aristotle's notion of practical wisdom and prudence.

Often it is asserted that theory is rigorous and practice is ad hoc. This is not the case. Practical rigour is different from theoretical rigour. Practice requires a use of rational judgement that transcends strict logical rules to deal with uncertainty. Engineers create practical solutions despite the limitations of our understanding. They use appropriate models, find dependable evidence and with a vision of what is needed create solutions that work. Practical rigour requires practical foresight and analysis of all hindsight. The possible unintended consequences of human action are legion, and the rigour of practice is about anticipating and managing them. The values of science are clear cut (truth and precision); the values in engineering are many and various, hard and soft, and often almost impossible to measure. Scientific rigour requires selective inattention to the difficulties with which we cannot yet cope. Practical rigour does not have that luxury - it must include everything that is relevant.

A quality of discerning and judging - a way of looking at things with an ability to see the world in a coherent picture. It has been argued that a wise person has to have knowledge, ethicalness and appropriate skills to a high degree. It is having an appropriate attitude with an ability to cut through to the essential goals and aims and having the will and purpose to keep these in focus. It is to do with finding simplicity in complexity. More fundamentally, it is to do with worldviews and the way a person constructs the world in which they operate, which in engineering is to do with having appropriate models to fit the situation. Practical wisdom implies practical rigour, which in turn implies practical intelligence, which implies practical experience. In other words, practical experience is necessary for all of the others but it is not sufficient because there must be reflective learning from that experience.

That which is done to change a state of the world whether by human agency or a physical field. A basic tool for describing a system. It is a way of getting from where you are now to where you want to be. A process can be viewed and described from many points of view (safety, functionality, cost, etc.). It can be used as a central idea from which all others can be 'hung'. It is flexible and can be used to manage change. Answers to the questions 'who', 'what', 'why', 'where', 'when' and 'how' enable you to describe a process. 'Why' identifies the purpose or potential that drives the change in 'who', 'what', 'where' and 'when' through the transformations identified by 'how'. It can be formulated as 'why = how (who, what, where, when)', although this should not be interpreted as a mathematical formula. The output of a process may be a product, but that in itself has a life cycle and is also a process. A number of process modelling tools are now available. 


\section{process model}

purpose

quality

randomness

reflective practice

resilience

risk

robustness
An arrangement of processes such that the lower-level processes work together to achieve the purpose of the higher process. This approach to process mapping is consistent with the value management principle and deals with 'why' questions before 'how' questions.

The reason for doing something. The intention or objective. The result or effect that is intended. Purpose is the answer to the question 'Why are we doing this process?' The answer determines the models used. It is a question that civil engineers often do not ask, and as a consequence often they are not able to articulate to the client the value they have added, or they are immersed in interesting technical detail that is of secondary interest to the client. This is often at the root of the reason for their work being undervalued by non-technical people.

Fitness for purpose and degree of excellence at the same time. We make decisions about excellence based on our preferences in the choices we make to fulfil a purpose that includes function, cost, safety, aesthetics, sustainability, etc. Our preferences are based on our values. Worth is a measure of the value we give to something. Excellence is the state of having the highest worth (i.e. the highest value and the highest quality). Fitness for purpose is quality - it is important to see that quality is not just about the level of functionality, it is about the total purpose of a project and its context (i.e. total quality). The degree of quality is a measure of how good the totality of what we are getting is relative to what we want from any process. Understanding our values is central to delivering quality - of being clear about the relationship between excellence and fitness for purpose.

Lack of a specific pattern in some data (e.g. a ticket in the UK National Lottery). But how can we know if a number is truly random? We test any sequence (indeed any data), and look for any pattern. If we find one, then the information is not random. However, if we search and search and find no pattern, then we can become more confident that the data are random. However, there is no final test to establish randomness - we can only say that something seems to be random or there is strong evidence that it is random. Complex patterns do occur in random data, but only over populations, and it is these patterns that are studied in probability theory and statistics. If there is no pattern even in a population, then everything has an equal chance - and that represents a state of maximum information entropy or maximum disorder in the information. Randomness is only one aspect of uncertainty but it is the only uncertainty represented in probability theory. Both have been used extensively in, for example, reliability theory, and so randomness is relevant to uncertainty in engineering problems.

Acting with practical wisdom and rigour - the way professionals do their work. They perceive the world, they reflect upon it and they act. They do it with rigour, wisdom and foresight. Practitioners need to reflect critically on what they do and the decisions they make before and after an event. Much of the expertise of practical professionals lies in their ability to use these skills in action in complex and unpredictable situations.

The ability of a system to withstand or recover quickly from challenging conditions; to respond by detecting, preventing and, if necessary, handling disruptive challenges. It requires planning, learning, resources, watchfulness, coordination and cooperation (cf. robustness).

The chance or likelihood of a specific state of the world, or outcome, at some time in the future combined with the consequences that will follow and set in a particular context. Usually the state of the world is defined as an unwanted event (e.g. a hazard that will result in harm). However, it could be an unintended benefit that represents an opportunity to add value (see uncertainty). A risk for one person may be an opportunity for another (e.g. risk of theft may be an opportunity for an insurance broker). Risk depends on context (e.g. the risk to the driver of a car driving at full speed on the highway is more than on a purpose-designed track). It may be helpful to think about risk as a description of the degree to which evidence about the past and current state of a process together with projected future states will lead to success or failure in the future. You may describe the process in terms of activities (e.g. travelling by car or climbing some scaffold); in terms of hazards (e.g. a live electric wire or flooding); in terms of events (e.g. an accident or industrial action); or in terms of consequences of events (e.g. financial loss or death). Perhaps one of the biggest difficulties is how to measure risk. Probability theory is often used, but relies on a closed-world model that is clearly hardly ever the case in wicked problems.

Sturdy, resilient, durable and hard wearing. A system that is robust is not vulnerable (i.e. the consequences of possible damage are not out of proportion to the magnitude of that damage). For example, minor damage on a bridge by a car should not cause the bridge to collapse. There is little theory about robustness, but it is clear that sturdiness in all limit states is important. 
silo

\section{socio-physical system soft system}

subjective

subsidiarity

sufficiency

sustainability

system

systems thinking

tame problems
Organisational silos occur when people get trapped inside their specialist departments, social groups, teams, or pockets or compartments of knowledge. Hence the integration and 'joining up' of systems is problematical - data and information about interconnectivities at organisational, commercial and policy levels is poor, and disjointed approaches to governance and policy create perverse incentives and conflicting actions. There are also limitations on capacity, inefficiencies, poor reliability, low adaptability and missed opportunities.

Any system where both social and physical issues must be considered.

Human and social systems involving people. Our ability to model them and hence predict them dependably is very poor. Soft systems comprise action, reaction and intention (cf. hard systems). Perceptions and private thoughts that cannot be shared. It is a concept widely misunderstood by engineers, with the consequence that they tend to undervalue their own skill of engineering judgement. We reach out to the world through our senses. We hear noises, we see things and we touch them. But what is the world really like? If our eyes were sensitive to X-rays, we would see the world quite differently. Our mental models would be quite different. There are also perceptions and private thought that cannot be shared - they are truly subjective (e.g. the pain in my stomach). However, there are many perceptions that we can share, and by discussion we agree about certain things - they are inter-subjective (e.g. the colour of a fabric). We construct ideas and relationships and we measure things in ways that are repeatable and dependable, and they lead to objective testable knowledge (e.g. science that exists outside any one person's mind and is therefore objective). Engineering judgement relies on experience and personal characteristics, and while it is not easily measured and demonstrably dependable except in hindsight, it is very valuable. It is not arbitrary and subjective and it is not easily measured; nevertheless, when it is good it is dependable and objective.

The idea that systems models should be created at the lowest practical level consistent with delivering their purpose.

1. The state of being enough, being adequate for what is required to be done or achieved. A sufficient condition is one that, if fulfilled, is adequate. Condition A is sufficient for condition B if when A occurs then so will B. We need to note that even though B always occurs whenever A occurs, it is possible for B to occur without A (e.g. good design is sufficient for safe design). Also, in the logical implication 'if A then B' or 'A implies B', A is sufficient for B and B is necessary for A (e.g. 'if (good design) then (safe design)').

2. In interval probability theory using the Italian flag, sufficiency is a conditional measure of the degree to which the success of a subprocess $\mathrm{E}$ is required for the success of a super-process $\mathrm{H}$ (i.e. $p(\mathrm{H} / \mathrm{E}))$. It is the evidence for $\mathrm{H}$ given $\mathrm{E}$ expressed as an interval probability.

Keeping something going over time - keeping from failing or enduring without giving way. The ability of a development to meet the needs of the present without compromising the ability of future generations to meet theirs. Sustainable engineering requires us to become explicitly aware of certain values such as (1) a concern for the needs and rights of future generations; (2) an appreciation of the importance of diversity (e.g. biodiversity); (3) a responsible and precautionary attitude to risk when there are significant 'don't knows' so that the consequences of decisions may, as far as is practically possible, be reversible; and (4) achieving a balance between various processes (physical, business, social, etc.). There is a real need to recognise the interdependence of systems, and especially between people and the physical world.

An overused word with many meanings and uses. Used loosely, it just refers to any group of connected objects. More precisely, as used in systems theory, it is a complex whole with a set of interacting parts as a connected network or mechanism that has emergent properties that explain why the whole can be more than the sum of its parts. A hard system is a physical one that can be explained in terms of action and reaction. It is always embedded in a soft system involving people with action, reaction and intention because the only way we have of understanding these systems is through the filters of human sensory, neural and intellectual apparatus. System identification is about deciding what is to be part of the system and what is in the meta-system of context.

Systems thinking is not a subject like the strength of materials or mathematics; rather, it is a way of thinking - a way of tackling problems. There are three important features: holons, connectivity and a new view of process. Thus, the systems thinker looks for a hierarchy of interacting processes to build into a process model. Attributes are then attached, based on questions as to why (purpose), how (method), who, what, where and when (the change parameters).

Problems that are linear, manageable and controllable. They are sometimes referred to as simple problems. 
uncertainty

value

vision

vulnerability

wicked problem

worldview
The absence of precise and complete knowledge. Managing uncertainty is a key issue. Decisions depend on the past experiences and case histories, the present state of affairs through observation and audit, and the future through prediction - scientific or otherwise. We try to anticipate unintended consequences and to make contingency plans. Unintended consequences can be a benefit as well as a threat. If we are ready to manage them, then we can take advantage of the good ones and minimise the disadvantages of the bad ones. Uncertainty consists of fuzziness, incompleteness and randomness.

1. The regard, merit, importance or worth given to something. It is the basis for showing a preference (i.e. making a choice). The criteria on which our values are based.

2. Material or monetary worth.

3. The magnitude of a mathematical variable (e.g. the value of $x$ is 2 or $x=2$ ).

The ability to articulate what the future will or could be like with imagination and wisdom. The shared vision of a group is their shared mental model of the future they seek to create. It captures their values and expresses their larger sense of purpose. Vision statements are often condemned as having little content. However, just like mission statements, the value is in the process by which they are developed. If they are written by top management with no consultation, then they are ineffective. However, if they express beliefs and collective personal visions, they can be extremely effective. Leaders must 'walk the talk' to obtain commitment. Such belief is created by actions not words. Effective teams and organisations have a clear sense of purpose expressed through vision, mission, aims and objectives.

A property of a system where small damage can cause disproportionate consequences (e.g. the Ronan Point high-rise block of flats in London in 1968 was a vulnerable structure because a small domestic gas explosion in one apartment caused the whole side of the building to collapse). Vulnerability also concerns low-chance, high-consequence risks. The theory of vulnerability is underdeveloped and needs much more attention for all complex systems - from computer networks to engineering structures.

Problems and situations that do not seem to yield to easy solutions - contrasted with tame problems (cf. messy problems). There seem to be so many interlocking issues and constraints that you don't seem to understand the problem until you have developed a solution. There are so many people involved it seems more like a social process. The constraints change over time and the goalposts shift. The way we look at the world, our point of view. We attribute meaning to things by interpreting them in the light of our education and experience. Thus, the same issue will be formulated as an economic problem by an economist, an engineering problem by an engineer, a political problem by a politician, and so on. 